Revista Educação e Políticas em Debate - v. 8, n. 2, p.233-253, mai./ago. 2019 - ISSN 2238-8346

\title{
GO PISA! Indicativos para elaboração de políticas públicas educacionais
}

GO PISA! Indicators for the elaboration of educational public policies

GO PISA! Indicateurs pour l'élaboration de politiques publiques d'éducation

Resumo: Este artigo tem como base a avaliação do PISA (Programme for International Student Assessment) realizada em 2015, mais especificamente a coleta de dados com foco na atuação de estudantes e professores do Brasil, com o objetivo de apresentar indicativos para possível elaboração de políticas públicas para educação no País. O estudo constitui-se da análise de informações, tomando como metodologia as diretrizes de comparação da efetividade educacional com os países participantes e os resultados obtidos com os alunos brasileiros que atendem muitos quesitos, principalmente da rede federal de educação. A análise demonstra que são necessários investimentos em formação dos professores, infraestrutura nas escolas e definição da continuidade dos meios de avaliação por meio de políticas de Estado.

Palavras-chave: PISA. Educação Comparada. Políticas Públicas.

Abstract: This paper is based on the evaluation of the PISA (Program for International Student Assessment) held in 2015, specifically the collection of data focused on the performance of students and teachers in Brazil, with the aim of presenting indicatives for the possible elaboration of public policies for education in the country. The study is based on the analysis of information, taking as a methodology the guidelines for comparing educational effectiveness with the participating countries and the results obtained with Brazilian students that meet many requirements, especially the federal education network. The analysis demonstrates that

1Doutorando e Pesquisador do Programa de Pós-Graduação em Educação da Universidade Católica de Brasília. E-mail:

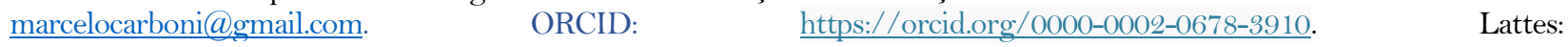
http://lattes.cnpq.br/3819081103019923.

2Doutor e Docente do Programa de Pós-Graduação em Educação da Universidade Católica de Brasília. E-mail: renatoorios@gmail.com. $\quad$ ORCID: https://orcid.org/O000-0002-9345-2529..$\quad$ Lattes: http://lattes.cnpq.br/7692528705135758.

3Especialista e aluno-especial do Mestrado do Programa de Pós-Graduação em Educação da Universidade Católica de Brasília. E-mail: thebergeramos@hotmail.com. Lattes: http://lattes.cnpq.br/1317810337459037. 
Revista Educação e Políticas em Debate - v. 8, n. 2, p.233-253, mai./ago. 2019 - ISSN 2238-8346

investments are necessary in teacher training, infrastructure in schools and definition of the continuity of the means of evaluation through State policies.

Keywords: PISA. Comparative Education. Public Policies.

Résumé: Cet article est basé sur l'évaluation du PISA (Programme international pour le suivi des acquis des élèves) tenue en 2015, en particulier la collecte de données sur les performances des élèves et des enseignants au Brésil, dans le but de présenter des indicateurs pour L'étude est basée sur l'analyse des informations, en prenant comme méthodologie les directives pour comparer l'efficacité de l'enseignement avec les pays participants et les résultats obtenus avec des étudiants brésiliens répondant à de nombreuses exigences, en particulier le réseau fédéral d'éducation. L'analyse montre que des investissements sont nécessaires dans la formation des enseignants, l'infrastructure dans les écoles et la définition de la continuité des moyens d'évaluation à travers les politiques de l'État.

Mots Clés: PISA. Éducation comparée. Politiques Publiques.

Recebido em: 05 de setembro de 2019 Aceito em: 04 de dezembro de 2019

\section{Introdução}

O Programa Internacional de Avaliação de Alunos (PISA) é uma iniciativa da Organização para Cooperação e Desenvolvimento Econômico - OECD (The Organisation for Economic Co-operation and Development) que iniciou em 2000 e ocorre a cada três anos de forma espontânea e não-obrigatória para países que desejam participar. Em 2015 foram 70 países participantes, sendo 35 membros da OECD e 35 países-parceiros incluindo o Brasil.

O foco do PISA é medir por meio desta avaliação, o desempenho de estudantes com 15 anos de idade e que estejam próximos ao término da escolaridade obrigatória, verificando se ele obteve conhecimentos e habilidades essenciais para inserção na sociedade e no mercado de trabalho. É objeto desse exame verificar se o estudante domina assuntos e conhecimentos que extrapolam a sala de aula objetivando reproduzir situações e o que fazer com o que se aprendeu.

Com os resultados obtidos pelo PISA podemos definir novas práticas e políticas educacionais indicando mudanças assertivas, podendo definir melhorias em comparação com os sistemas educacionais de outros países estabelecendo metas mensuráveis e alcançáveis de crescimento da escolaridade ou anos de instrução. 
A avaliação do PISA que ocorreu em 2015 teve como enfoque a ciência, a leitura, a matemática com resolução de problemas. Foi a primeira vez que a avaliação foi realizada utilizando computador como meio, salvo os países que preferiram utilizar o formato tradicional em papel, neste último caso limitou-se a questões que pudessem medir igualmente o desempenho.

Cerca de 540 mil alunos responderam à avaliação representando 72 países e economias participantes, além de responderem questionário sobre a escola que frequentam, experiências de aprendizagem e o lugar onde moram. Também foram convidados a responder outros questionários os diretores e os professores de escolas (sistema e ambiente de aprendizagem).

O PISA se baseia na Teoria de Resposta ao Item - IRT (Item Response Theory), que é uma avaliação em que as propriedades técnicas produzem resultados que mudam em função da amostragem, desenvolve assim, instrumentos de medida cuja característica é de não ser influenciada por um grupo de referência, e isso passa a definir a escala absoluta (PINI, 2012).

Os países que usam essas referências teóricas e metodológicas têm como objetivo a harmonização do próprio sistema educativo e tem o interesse de analisar em que medida eles estão atingindo os critérios internacionais (MORGAN, 2011).

É necessário evidenciar que o processo de expansão do PISA em países da América Latina como o Brasil resulta, em relação à produção de dados estatísticos sobre a educação, em um efeito de desalinhamento (CARVALHO, 2012) no nível metodológico, logístico e analítico (VILLANI, 2018).

Constatamos que o PISA, como aplicado no Brasil, reflete uma representação parcial da realidade escolar brasileira que se apresenta complexa, muito diversificada e com um nível de desigualdade econômica e cultural forte (VILLANI, 2018).

De acordo com Morgan (2011, P.4), a OCDE com a realização do PISA conseguiu se posicionar como líder na produção dos dados estatísticos no mundo da educação:

Criando o PISA a OCDE posicionou-se como líder na produção dos dados estatísticos em nível internacional e na produção de infraestrutura que existe dentro de uma arquitetura global da educação. Essa estrutura global inclui diferentes organizações internacionais chaves como o Banco Mundial, Fundo Monetário Internacional, Nações Unidas. Organizações regionais como a União Europeia são também conectadas com ele. Além disso existe o adversário da OCDE na área de medidas em educação - Associação Internacional para a Avaliação do Desempenho Escolar (IEA) que foi criada sob a égide da UNESCO e do Instituto pela Educação (UIE). 
Revista Educação e Políticas em Debate - v. 8, n. 2, p.233-253, mai./ago. 2019 - ISSN 2238-8346

Ressalta-se que, além disso, a OCDE produz uma influência política de tipo soft, já que não tem instrumentos legais para a promoção das políticas educativas (PETTERSSON, 2014). É o que ocorre no Brasil, salvo o fato de ter conseguido imprimir no Plano Nacional de Educação (PNE), aprovado como Lei Federal, nº 13.005 (BRASIL, 2014), em junho de 2014, na estratégia 7.11, da sua meta 7, a proficiência do PISA como um indicador da qualidade da educação no país (VILLANI; OLIVEIRA, 2018).

Essa dinâmica, determinada por dita abordagem, no contexto brasileiro se desenvolve com a implementação do Índice de Desenvolvimento da Educação Básica (IDEB). Com a criação do IDEB em 2007, no bojo do Plano de Desenvolvimento da Educação (PDE), como uma referência para o planejamento e orientação de políticas e financiamento público para a educação em âmbito nacional, tem-se a consumação da lógica econômica para a gestão e organização da educação pública (VILLANI; OLIVEIRA, 2018).

Usando os resultados da Prova Brasil e do Sistema Nacional de Avaliação da Educação Básica (SAEB), o IDEB passa a ter impacto direto sobre a regulação dos resultados dos estudantes, mas também das práticas dos outros atores escolares, pois interfere nas lógicas organizativas das escolas, incluindo seus arranjos curriculares e o planejamento da gestão (VILLANI; OLIVEIRA, 2018).

A partir disso, dissemina-se pelo país a regulação por resultados, desde os mais distantes municípios até as grandes capitais, as políticas educacionais passaram a estabelecer metas e a negociar sua realização com as escolas. Assiste-se aí à introdução da contratualização entre escolas e secretarias, tendo as médias do IDEB como parâmetros a serem conquistados (OLIVEIRA; JORGE, 2015).

Sendo assim, o objetivo de estudo dos dados coletados sobre os quais tratam este artigo é verificar a percepção da aderência da aplicação do PISA no Brasil em relação aos paísesmembros e participantes, tendo em vista a diversidade e as características diferenciadas de um país com dimensões continentais. Na seção 2 são apresentadas as características e as informações da amostra selecionada para aplicação do PISA no Brasil.

Na seção 3 são apresentados os resultados da avaliação de Ciências, os resultados da avaliação de Leitura, os resultados da avaliação de Matemática, os resultados da avaliação de Letramento Financeiro, os resultados da avaliação da Resolução Colaborativa de Problemas e os resultados das Evidências dos Questionários do Professor. Por fim, na seção 4 são discorridas as considerações finais desta análise dos dados produzidos. 
Revista Educação e Políticas em Debate - v. 8, n. 2, p.233-253, mai./ago. 2019 - ISSN 2238-8346

\section{PISA no Brasil}

No Brasil a coordenação do PISA é realizada pelo Instituto Nacional de Estudos e Pesquisas Educacionais Anísio Teixeira (INEP). Nos anos 1990, com a redemocratização da sociedade e a aprovação da Constituição Federal de 1988, que mais direitos garantiu ao conjunto da população na história do país, o Inep passa a ter como principal tarefa a avaliação e a produção de conhecimentos sobre o sistema escolar brasileiro (FERREIRA, 2008; SCHWARTZMAN, 2013).

A avaliação é trienal, sendo o público brasileiros estudantes entre 15 anos e 3 meses (completos) e 16 anos e 2 meses (completos) matriculados a partir da $7^{\mathrm{a}}$ série da educação básica. Em 2015, o foco foi ciências, além de leitura e matemática, e houve, avaliação da resolução colaborativa de problemas e letramento financeiro. Os instrumentos utilizados no PISA envolve testes e questionários que fornecem três tipos principais de resultados: indicadores do perfil básico de conhecimento e habilidades do aluno; indicadores dessas habilidades relacionadas a variáveis demográficas, sociais, econômicas e educacionais; e indicadores de tendências que acompanham o desempenho dos estudantes e monitoram os sistemas educacionais ao longo do tempo.

Com base nos dados informados pelo INEP em 2015, o universo dos alunos brasileiros elegíveis é apresentado na Tabela 1.

Tabela 1: População definida no sistema de referência x desejada na avaliação- PISA 2015

\begin{tabular}{|l|r|}
\hline População definida no sistema de referência & 3.430 .255 \\
\hline População estimada de jovens brasileiros com 15 anos em 2015 & 400.438 \\
\hline População brasileira de 15 anos matriculada em instituições de ensino no 6 ${ }^{\circ}$ ano ou em ano inferior & 2.853 .388 \\
\hline População brasileira de 15 anos matriculada em instituições de ensino a partir do $7^{\circ}$ ano (elegíveis) & 67.768 \\
\hline Número de escolas com estudantes elegíveis para o PISA 2015 & 6.431 \\
\hline Exclusão & 62.763 \\
\hline $\begin{array}{l}\text { Número de escolas excluídas devido à inacessibilidade geográfica ou por incompatibilidade entre a } \\
\text { língua de instrução e a língua portuguesa }\end{array}$ & 61.337 \\
\hline Número esperado de estudantes das instituições excluídas & 2.790 .625 \\
\hline População desejada na avaliação & \\
\hline Número de escolas associadas à população desejada (após exclusões) & \\
\hline População estimada de estudantes elegíveis para o PISA 2015 (após exclusões) & \\
\hline
\end{tabular}

Fonte: OCDE, INEP (2015)

Foram selecionados estudantes das 27 unidades da Federação. Todos os estudantes elegíveis a partir do $7^{\circ}$ ano foram incluídos na amostra (em função da ampliação do Ensino Fundamental para 
nove anos de duração pela Lei $\mathrm{n}^{\circ}$ 11.274, de 6 de fevereiro de 2006 (BRASIL, 2006), sendo que foi a primeira vez no Brasil que a aplicação do PISA foi totalmente informatizada.

Foi gerada uma amostra de 23.141 estudantes de 841 escolas, que foram selecionados com base na lista encaminhada pelas escolas e que tiveram pelo menos uma resposta nos testes cognitivos ou respondeu a pelo menos um item do questionário do estudante do PISA 2015. O perfil do estudante brasileiro no PISA 2015: 77,7\% matriculados no ensino médio; 73,8\% estudantes da rede estadual; 95,4\% localizados em área urbana; 76,7\% localizados no interior; e $51,5 \%$ estudantes do sexo feminino.

\section{a) Resultados da Avaliação de Ciências no PISA}

Os requisitos para o letramento científico sob a ótica da OCDE no PISA 2015 são ter conhecimento de conceitos e teorias e conhecimento sobre os procedimentos e práticas comuns associadas com a investigação científica. O estudante deve demonstrar capacidade de refletir e de se envolver num diálogo crítico sobre os assuntos relacionados à ciência e tecnologia, bem como compreensão de como a ciência é construída. O teste cognitivo de ciências é baseado nas dimensões da matriz de referência apresentada na Tabela 2:

Tabela 2: Dimensões da matriz de referência - PISA 2015

\begin{tabular}{|c|c|c|c|c|c|}
\hline \multicolumn{3}{|c|}{ Dimensões da matriz de referência } & \multicolumn{3}{|c|}{ Outras categorias } \\
\hline $\begin{array}{l}\text { Competências } \\
\text { científicas }\end{array}$ & $\begin{array}{l}\text { Tipos de } \\
\text { conhecimento }\end{array}$ & $\begin{array}{l}\text { Sistemas de } \\
\text { conteúdo }\end{array}$ & $\begin{array}{l}\text { Tipos de } \\
\text { resposta }\end{array}$ & $\begin{array}{l}\text { Demanda } \\
\text { cognitiva }\end{array}$ & Contextos \\
\hline $\begin{array}{l}\text { Explicar } \\
\text { fenômenos } \\
\text { cientificamente }\end{array}$ & Conteúdo & Sistemas físicos & $\begin{array}{l}\text { Escolha } \\
\text { múltipla } \\
\text { simples }\end{array}$ & Baixa & Pessoal \\
\hline $\begin{array}{l}\text { Avaliar e planejar } \\
\text { experimentos } \\
\text { científicos }\end{array}$ & Procedimental & Sistemas vivos & $\begin{array}{l}\text { Escolha } \\
\text { múltipla } \\
\text { complexa }\end{array}$ & Média & Local/Nacional \\
\hline $\begin{array}{l}\text { Interpretar dados } \\
\text { e evidências } \\
\text { cientificamente }\end{array}$ & Epistemológico & $\begin{array}{l}\text { Sistema Terra } \\
\text { espaço }\end{array}$ & $\begin{array}{l}\text { Resposta } \\
\text { construída }\end{array}$ & Alta & Global \\
\hline
\end{tabular}

Fonte: PISA 2015 Assessment and Analytical Framework: Science, Reading, Mathematical and Financial

$$
\text { Literacy OCDE (2017) }
$$

Os estudantes brasileiros responderam dois blocos de itens de ciências e dois blocos de itens de outros domínios com 36 combinações distintas. Os itens da competência "interpretar dados" e "evidências cientificamente" obtiveram o maior percentual de respostas corretas 
Revista Educação e Políticas em Debate - v. 8, n. 2, p.233-253, mai./ago. 2019 - ISSN 2238-8346

(33,7\%), seguido das competências "explicar fenômenos cientificamente” (30,7\%) e "avaliar e planejar experimentos científicos" (26,3\%).

A dificuldade dos estudantes brasileiros dos itens sobre conhecimento epistemológico foi mais difícil (22,1\% dos acertos) do que os que abordam os outros dois tipos de conhecimento. Por outro lado, os itens que abordam conhecimento de conteúdo tiveram em geral, a maior média de acertos $(32,6 \%)$ dos brasileiros.

Nos sistemas de conteúdo, independente da média de desempenho geral do país, as diferenças de dificuldade em relação aos três sistemas (físicos, vivos e Terra espaço) foram relativamente pequenas. Itens relacionados ao contexto pessoal foram considerados mais fáceis do que os de contexto local e global (OCDE; INEP,2015).

Os estudantes brasileiros tiveram maior dificuldade nos itens de resposta aberta, seguidos pelos de múltipla escolha complexa e simples, também observada em outros países. A diferença entre o índice de dificuldade dos itens de resposta aberta e dos itens de escolha múltipla simples provocou uma redução de 22,8\% no percentual de acertos (OCDE; INEP,2015).

A demanda cognitiva está fortemente associada à dificuldade do item. Itens de demanda cognitiva alta apresentaram maior dificuldade para os estudantes, inclusive para países com maior desempenho. Alguns itens se destacam como indicadores de pontos fortes e fracos do desempenho dos estudantes brasileiros em Ciências:

- Pontos fracos: Interpretar dados e evidências cientificamente, de conhecimento procedimental, de resposta aberta e de múltipla escolha complexa;

- Pontos fortes: Explicar fenômenos cientificamente, de conhecimento de conteúdo, resposta do tipo múltipla escolha simples.

O escore médio do estudante brasileiro em ciências é de 401 pontos e de estudantes dos países-membros da OCDE é de 493 pontos. Abrindo a pontuação do estudante brasileiro por rede de ensino temos:

- Rede municipal: 329 pontos

- Rede estadual: 394 pontos

- Rede federal: 517 pontos

- Rede particular: 487 pontos

O desempenho da rede federal supera a média nacional, embora não seja estatisticamente diferente da rede particular. O resultado inferior na rede municipal se deve ao foco do ensino 
fundamental. O intervalo de confiança da média do Brasil em ciências está entre 396 e 405 pontos. Os 10\% dos estudantes brasileiros com pior desempenho obtiveram média igual a $391 \mathrm{e}$ os $10 \%$ melhores 522 .

Podemos observar no Gráfico 1 abaixo, a comparação do desempenho com outros países:

Gráfico 1: Desempenho dos estudantes submetidos à avaliação de ciências - PISA 2015

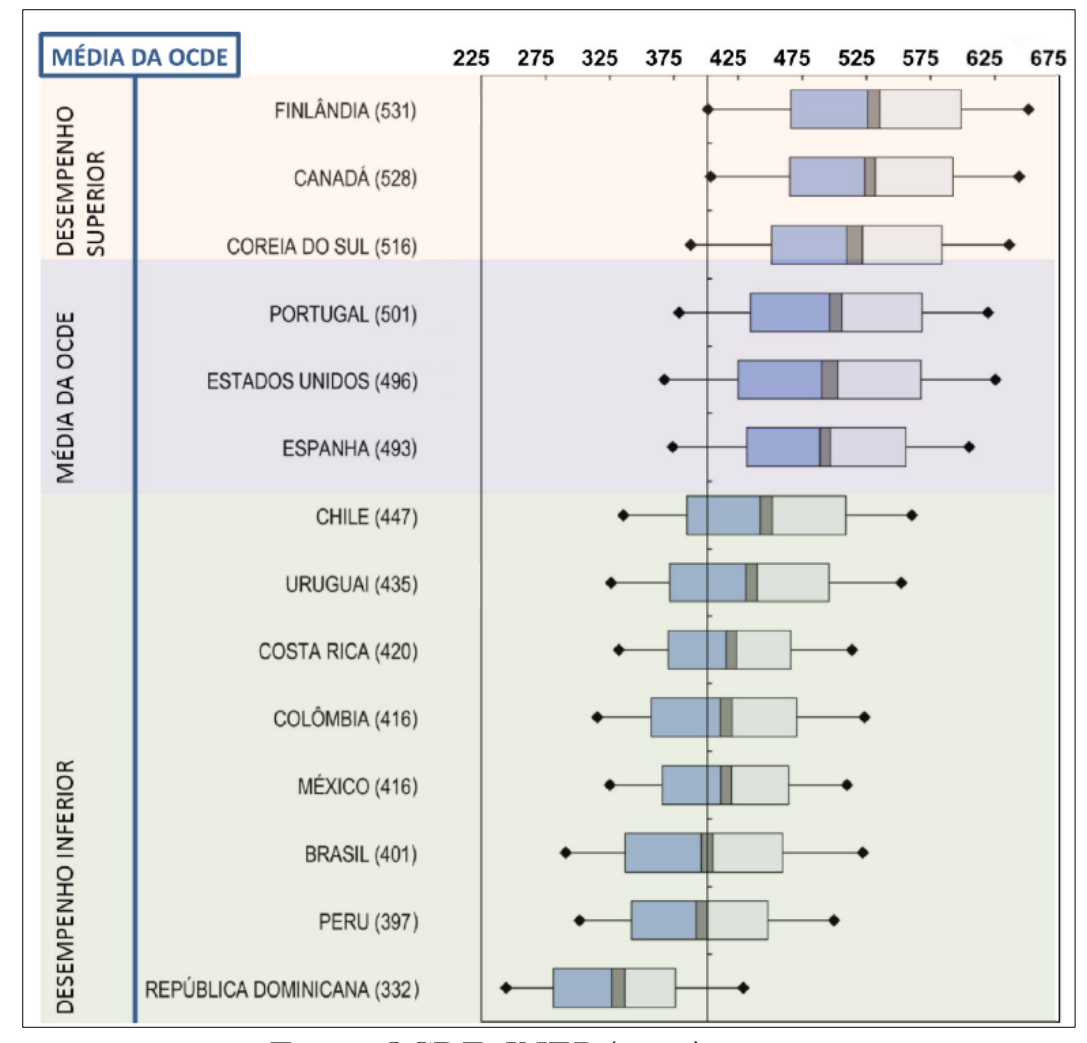

Fonte: OCDE, INEP (2015)

O desempenho médio dos estudantes brasileiros em ciências somente está à frente dos dominicanos e peruanos, mas se formos comparar com a rede federal nos classificamos com desempenho superior.

\section{b) Resultados da Avaliação de Leitura}

Os requisitos para o letramento em leitura sob a ótica da OCDE no PISA 2015 são compreender, usar, refletir, sobre e envolver-se com os textos escritos, a fim de alcançar um objetivo, desenvolver conhecimento e potencial e participar da sociedade. A avaliação é construída sobre três características de tarefas maiores para garantir uma ampla cobertura do domínio: 
Revista Educação e Políticas em Debate - v. 8, n. 2, p.233-253, mai./ago. 2019 - ISSN 2238-8346

- Situação: refere-se à gama de contextos ou finalidades amplas aos quais se aplica a leitura;

- Texto: refere-se aos materiais lidos;

- Aspecto: refere-se à abordagem cognitiva que determina como os leitores se envolvem com o texto. As características do domínio avaliados são apresentadas na Tabela 3:

Tabela 3: Características do domínio avaliado - PISA 2015

\begin{tabular}{|c|c|c|c|}
\hline Situação & Formato de texto & Tipos de texto & Aspectos \\
\hline Pessoal & Contínuo & Descrição & $\begin{array}{c}\text { Localizar e recuperar } \\
\text { informação }\end{array}$ \\
\hline Pública & Não-contínuo & Narração & Integrar e interpretar \\
\hline Educacional & Múltiplos & Exposição & Refletir e analisar \\
\hline Ocupacional & Combinados & Argumentação & \\
\hline & & Instrução & \\
\hline & & Interação & \\
\hline
\end{tabular}

Fonte: PISA 2015 Assessment and Analytical Framework: Science, Reading, Mathematical and Financial

$$
\text { Literacy OCDE (2017) }
$$

A dificuldade dos itens para estudantes brasileiros sobre leitura foi aproximadamente de 40\% dos itens, sendo que dois em cada cinco itens têm proporção de acerto igual ou superior a 50\%. A média de respostas corretas do Brasil foi de 41,4\%, abaixo da obtida por países da OCDE como Finlândia (65,5\%), Estados Unidos (60\%), Portugal (59,9\%) e Chile (51,9\%).

Alguns itens se destacam como indicadores de pontos fortes e fracos do desempenho dos estudantes brasileiros em ciências:

- Pontos fracos: lidar com textos da situação pública (textos e documentos oficiais, notas públicas e notícias), itens com textos no formato combinado, caracterizados pela junção de parágrafos em prosa e listas, gráficos, tabelas ou diagramas, itens que envolvem o aspecto integrar e interpretar;

- Pontos fortes: lidar com textos representativos de situação pessoal (e-mails, mensagens instantâneas, blogs, cartas pessoais, textos literários e informativos), itens com textos contínuos, definidos por sua organização em orações e parágrafos, e típicos em textos argumentativos, contos e romance, itens que envolvem o aspecto localizar e recuperar informação.

O escore médio em leitura do estudante brasileiro é de 407 pontos e de estudantes dos países-membros da OCDE é de 493 pontos. Abrindo a pontuação do estudante brasileiro por rede de ensino temos: 
Revista Educação e Políticas em Debate - v. 8, n. 2, p.233-253, mai./ago. 2019 - ISSN 2238-8346

- Rede municipal: 325 pontos

- Rede estadual: 402 pontos

- Rede federal: 528 pontos

- Rede particular: 493 pontos

O desempenho da rede federal supera a média nacional, embora não seja estatisticamente diferente da rede particular. O intervalo de confiança da média do Brasil em leitura está entre 402 e 413 pontos. Os 10\% dos estudantes brasileiros com pior desempenho obtiveram média igual a 279 e os 10\% melhores 539 (OCDE; INEP,2015).

Podemos observar no Gráfico 2 abaixo, a comparação do desempenho com outros países:

Gráfico 2: Desempenho dos estudantes submetidos à avaliação de leitura - PISA 2015

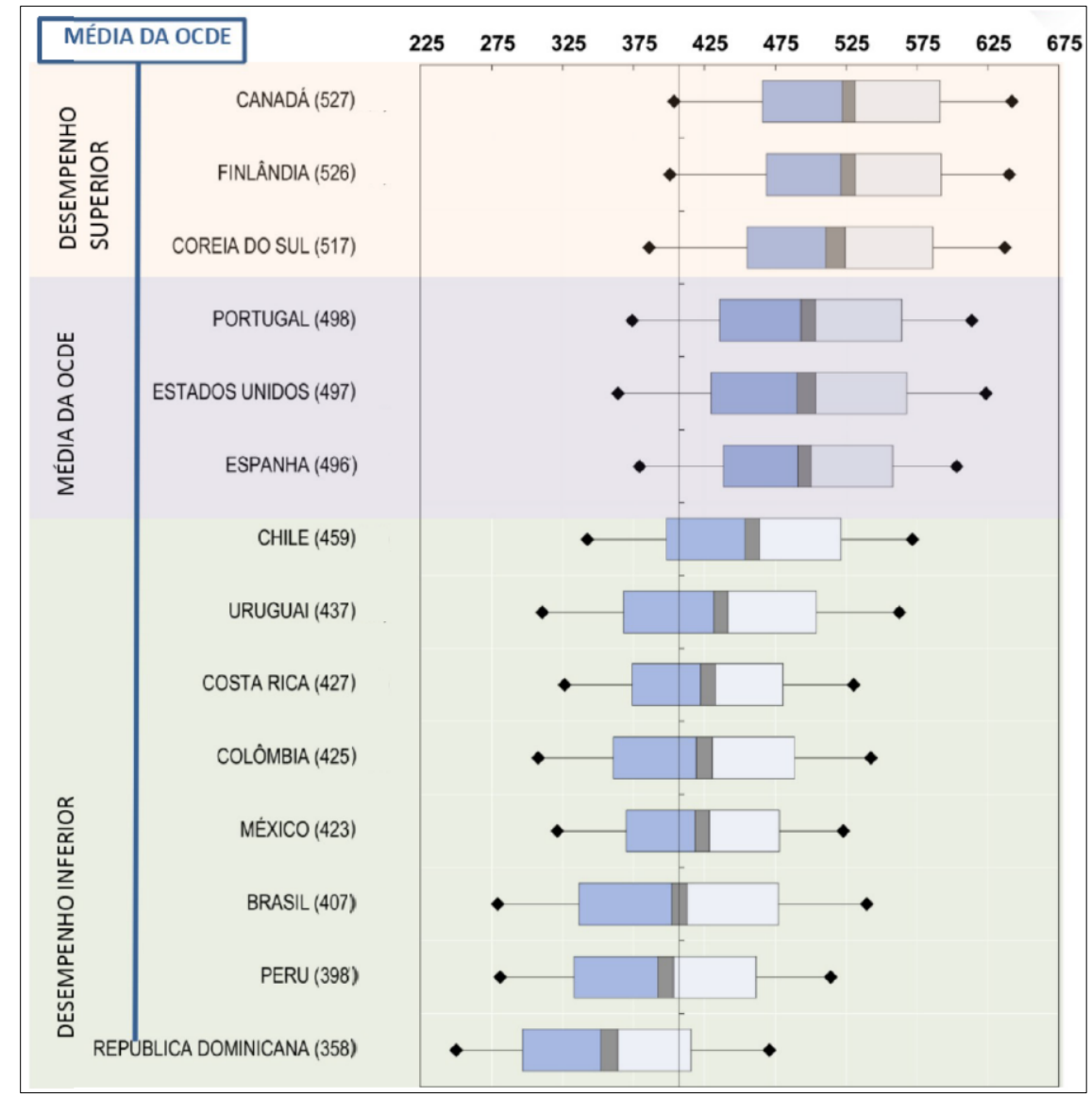

Fonte: OCDE, INEP (2015) 
Revista Educação e Políticas em Debate - v. 8, n. 2, p.233-253, mai./ago. 2019 - ISSN 2238-8346

O desempenho médio dos estudantes brasileiros em leitura somente está à frente dos dominicanos e peruanos, mas se formos comparar com a rede federal nos classificamos com desempenho superior, melhores que o Canadá.

\section{c) Resultados da Avaliação de Matemática}

Os requisitos para o letramento em matemática sob a ótica da OCDE no PISA 2015 são a capacidade de formular, empregar e interpretar a matemática em uma série de contextos, raciocinar matematicamente e utilizar conceitos, procedimentos, fatos e ferramentas matemáticas para descrever, explicar e prever fenômenos, reconhecer o papel que a matemática desempenha no mundo ao formar cidadãos construtivos, engajados e reflexivos que possam fazer julgamentos bem fundamentados e tomar as decisões necessárias (OCDE; INEP,2015). A avaliação de matemática é construída sobre três características:

- Formular situações matematicamente;

- Empregar conceitos, fatos, procedimentos e raciocínios matemáticos;

- Interpretar, aplicar e avaliar resultados matemáticos.

O modelo de letramento matemático é apresentado na Figura1:

Figura 1: Modelo de letramento matemático - PISA 2015

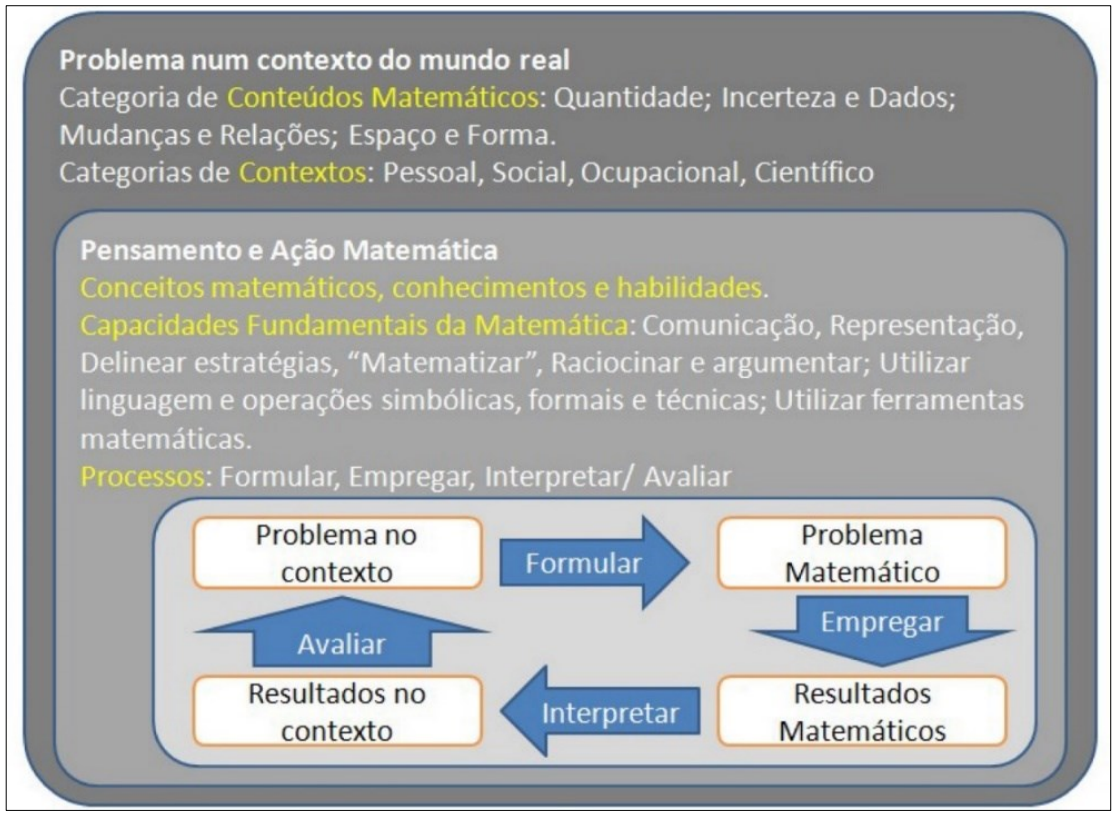

Fonte: PISA 2015 Assessment and Analytical Framework: Science, Reading, Mathematical and Financial Literacy

$\operatorname{OCDE}(2017)$ 
A dificuldade dos itens para estudantes brasileiros sobre matemática foi aproximadamente de $11,6 \%$ dos itens, sendo que um em cada nove itens têm proporção de acerto igual ou superior a 50\%. A média de respostas corretas do Brasil foi de 41\%. Os estudantes brasileiros têm melhor desempenho em itens sobre valor em dinheiro, razão e proporção e cálculos aritméticos. Isso significa que o manuseio do dinheiro ou a vivencia com fatos que gerem contas aritméticas ou proporções é uma realidade mais próxima (OCDE; INEP,2015).

Estudantes brasileiros têm desempenho mais baixo em itens que trabalham as propriedades das figuras geométricas, como o perímetro e a área, ou as características das figuras espaciais. A interação dinâmica com formas reais bem como suas representações mostrou-se como um conteúdo mais difícil e trabalhoso para os estudantes de 15 anos. A matemática envolvida diretamente com suas atividades cotidianas, família ou colegas apresentam maior facilidade. Problemas como preparação da comida, jogos, saúde pessoal ou finanças pessoais são situações mais facilmente matematizadas e resolvidas por eles mesmos (OCDE; INEP,2015).

O escore médio em matemática do estudante brasileiro é de 377 pontos e de estudantes dos países-membros da OCDE é de 490 pontos. Abrindo a pontuação do estudante brasileiro por rede de ensino temos:

- Rede municipal: 311 pontos

- Rede estadual: 369 pontos

- Rede federal: 488 pontos

- Rede particular: 463 pontos

O desempenho da rede federal supera a média nacional, embora não seja estatisticamente diferente da rede particular. O intervalo de confiança da média do Brasil em matemática está entre 371 e 383 pontos. Os 10\% dos estudantes brasileiros com pior desempenho obtiveram média igual a 267 e os 10\% melhores 496 (OCDE; INEP,2015).

Podemos observar no Gráfico 3 abaixo, a comparação do desempenho com outros países: 
Revista Educação e Políticas em Debate - v. 8, n. 2, p.233-253, mai./ago. 2019 - ISSN 2238-8346

Gráfico 3: Desempenho dos estudantes submetidos à avaliação de matemática - PISA 2015

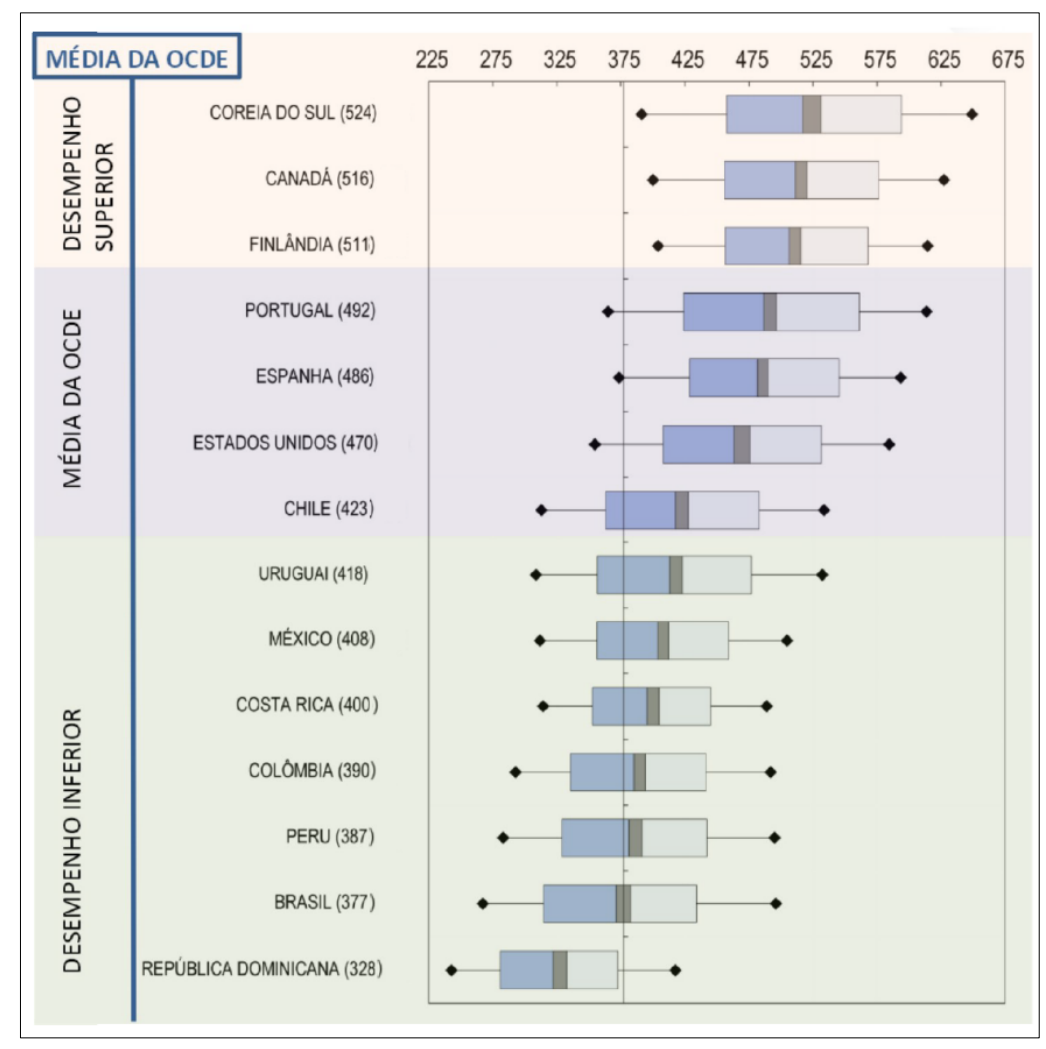

Fonte: OCDE, INEP (2015)

O desempenho médio dos estudantes brasileiros em matemática somente está à frente dos dominicanos, mas se formos comparar com a rede federal nos classificamos com desempenho da média da OCDE.

\section{d) Resultados da Avaliação de Letramento Financeiro}

Os requisitos para o letramento financeiro sob a ótica da OCDE no PISA 2015 são a capacidade de identificar produtos e termos financeiros comuns, reconhecer a diferença entre necessidades e desejos e tomar decisões simples sobre os gastos diários em contextos que eles provavelmente já experimentaram pessoalmente.

Estudantes socioeconomicamente favorecidos (25\% nível socioeconômico mais alto) obtêm 78 pontos a mais em letramento financeiro do que estudantes socioeconomicamente desfavorecidos (25\% nível socioeconômico mais baixo), equivalentes a mais de um nível de proficiência (a diferença média da OCDE é de 89 pontos). 
Revista Educação e Políticas em Debate - v. 8, n. 2, p.233-253, mai./ago. 2019 - ISSN 2238-8346

Apenas 2,6\% dos estudantes no Brasil apresentaram os melhores resultados em letramento financeiro, ou seja, conseguem analisar produtos financeiros complexos, resolver problemas financeiros não rotineiros e demonstrar uma compreensão do cenário financeiro mais amplo. O escore médio em letramento financeiro do estudante brasileiro é de 393 pontos e de estudantes dos países-membros da OCDE é de 489 pontos (OCDE; INEP,2015).

A avaliação sugere que algumas políticas podem ser implementadas pelos países e economias participantes:

- atender as necessidades dos alunos de baixo desempenho;

- enfrentar as desigualdades socioeconômicas o mais cedo possível;

- fornecer iguais oportunidades de aprendizagem para meninos e meninas;

- ajudar os alunos a aproveitar ao máximo as oportunidades de aprendizagem disponíveis nas escolas;

- envolver os pais, ao mesmo tempo que os jovens, na discussão do letramento financeiro;

- fornecer aos jovens oportunidades seguras para que possam aprender por meio de experiências fora da escola;

- avaliar o impacto das iniciativas dentro e fora da escola.

A proposição de inserção da matemática financeira básica nos currículos escolares é uma iniciativa que pode vir a contribuir com a mudança no desempenho apresentado e que reforça a preparação do cidadão para lidar com a economia doméstica no seu dia a dia.

\section{e) Resultados da Avaliação de Resolução Colaborativa de Problemas}

Na edição de 2015, o PISA inovou ao realizar a primeira avaliação em larga escala para testar habilidades de Resolução Colaborativa de Problemas (RCP) e responder à pergunta: Os estudantes de 15 anos de idade estão preparados para trabalhar coletivamente, de forma produtiva?

A competência de RCP é definida como a capacidade de um indivíduo engajar-se em um processo no qual dois ou mais agentes buscam resolver um problema, compartilhando entendimentos e esforços, usando seus conhecimentos e habilidades para chegar a uma solução.

Os itens da avaliação de RCP incluíam tarefas baseadas em conversas ou bate-papos nas quais os estudantes interagiam com um ou mais membros de um grupo para resolver um determinado problema em uma situação da vida real. Os estudantes se depararam com um conjunto de opções para selecionar a mais apropriada à resolução do problema proposto (OCDE; INEP,2015). 
Em média, nos países da OECD, 28\% dos estudantes são capazes de resolver apenas problemas de baixa complexidade e limitada colaboração, podem a ajudar a encontrar soluções para problemas simples. No Brasil isso ocorre com cerca de 60\% dos estudantes. Apenas $8 \%$ dos estudantes dos países-membros da OECD demonstram alta proficiência em RCP, ou seja, conseguem manter um reconhecimento de dinâmicas de grupo, assegurar que os membros da equipe atuem de acordo com os papéis previamente estabelecidos (OCDE; INEP,2015).

No Brasil, menos de $1 \%$ dos estudantes apresentam alta proficiência. Atitudes colaborativas são geralmente mais positivas quando os estudantes se engajam em atividades físicas ou têm mais aulas de educação física por semana. Estudantes que realizam trabalhos domésticos ou cuidam de outros membros da família valorizam mais o trabalho em equipe e o relacionamento. Considerando a média da OCDE, observa-se forte relação entre o desempenho em leitura, matemática e ciências e o desempenho em RCP.

\section{f) Resultados das Evidências dos Questionários do Professor}

Na edição de 2015, o PISA aplicou um questionário para professores de ciências com o objetivo de medir a satisfação do docente, que pode ser traduzida como um senso de realização e recompensa resultante da profissão. A satisfação do professor foi medida com base no questionário do professor na Tabela 4:

Tabela 4: Questionário do Professor de Ciências - PISA 2015

\begin{tabular}{|l|}
\hline $\begin{array}{l}\text { Gostaríamos de saber como você geralmente se sente quanto a seu emprego. De que } \\
\text { maneira você concorda ou discorda das seguintes afirmativas? }\end{array}$ \\
\hline 1. As vantagens em ser professor claramente ultrapassam as desvantagens. \\
\hline 2. Se eu pudesse escolher novamente, eu ainda escolheria trabalhar como professor. \\
\hline 3. Eu me arrependo de ter decidido tornar-me professor(a). \\
\hline 4. Pergunto-me se teria sido melhor escolher outra profissão. \\
\hline 5. Eu gosto de trabalhar nessa escola. \\
\hline 6. Eu recomendaria minha escola como um bom lugar para trabalhar. \\
\hline 7. Estou satisfeito com meu desempenho nessa escola. \\
\hline 8. No geral, estou satisfeito com meu emprego. \\
\hline \\
\hline Índice de satisfação com a profissão - construído com base nas respostas 1 a 4 \\
\hline Índice de satisfação com o atual emprego - construído com base nas respostas 5 a 8 \\
\hline
\end{tabular}

Fonte: Mostafa e Pál (2018) 
As perguntas deveriam ser avaliadas de acordo com o nível de concordância em uma escala de Likert de quatro pontos: Concordo plenamente, concordo, discordo e discordo plenamente. A amostra brasileira contou com 2.730 professores de ciências. Os resultados para índice de satisfação com a profissão e índice de satisfação com o atual emprego são apresentados respectivamente, nas tabelas 5 e 6 :

Tabela 5: Índice de satisfação com a profissão - PISA 2015

\begin{tabular}{|c|c|c|c|}
\hline \multicolumn{4}{|c|}{$\begin{array}{c}\text { Percentual de professores de Ciências que concordaram/concordaram } \\
\text { plenamente com as seguintes afirmativas }\end{array}$} \\
\hline $\begin{array}{l}\text { As vantagens em ser } \\
\text { professor claramente } \\
\text { ultrapassam as } \\
\text { desvantagens }\end{array}$ & $\begin{array}{c}\text { Se eu pudesse } \\
\text { escolher novamente, } \\
\text { eu ainda escolheria } \\
\text { trabalhar como } \\
\text { professor }\end{array}$ & $\begin{array}{l}\text { Eu me arrependo de } \\
\text { ter decidido tornar- } \\
\text { me professor }(\mathrm{a})\end{array}$ & $\begin{array}{l}\text { Pergunto-me se teria } \\
\text { sido melhor escolher } \\
\text { outra profissão }\end{array}$ \\
\hline $\begin{array}{c}75,7 \\
\text { Média OCDE }\end{array}$ & $\begin{array}{c}77,1 \\
\text { Média OCDE }\end{array}$ & $\begin{array}{c}10,3 \\
\text { Média OCDE }\end{array}$ & $\begin{array}{c}35,9 \\
\text { Média OCDE }\end{array}$ \\
\hline $\begin{array}{c}54,9 \\
\text { Brasil }\end{array}$ & $\begin{array}{c}68,4 \\
\text { Brasil }\end{array}$ & $\begin{array}{c}13,5 \\
\text { Brasil }\end{array}$ & $\begin{array}{c}43,4 \\
\text { Brasil }\end{array}$ \\
\hline
\end{tabular}

Fonte: Mostafa e Pál (2018)

Podemos observar na Tabela 5, menor índice de satisfação por parte dos professores brasileiros em relação à $\mathrm{OCDE}$, no que diz respeito às quatro perguntas realizadas, mas que não apresenta percepção de infelicidade por parte dos docentes com relação à carreira, ou seja, os professores brasileiros são resilientes mesmo com tantas dificuldades com relação à estrutura e condições de trabalho.

Tabela 6: Índice de satisfação com o emprego - PISA 2015

\begin{tabular}{|c|c|c|c|}
\hline \multicolumn{4}{|c|}{$\begin{array}{l}\text { Percentual de professores de ciências que concordaram/concordaram } \\
\text { plenamente com as seguintes afirmativas }\end{array}$} \\
\hline $\begin{array}{l}\text { Eu gosto de } \\
\text { trabalhar nessa } \\
\text { escola }\end{array}$ & $\begin{array}{c}\text { Eu recomendaria } \\
\text { minha escola como } \\
\text { um lugar bom para } \\
\text { trabalhar }\end{array}$ & $\begin{array}{l}\text { Estou satisfeito com } \\
\text { meu desempenho } \\
\text { nessa escola }\end{array}$ & $\begin{array}{c}\text { No geral, estou } \\
\text { satisfeito com meu } \\
\text { emprego }\end{array}$ \\
\hline $\begin{array}{c}89,2 \\
\text { Média OCDE } \\
\end{array}$ & $\begin{array}{c}83,5 \\
\text { Média OCDE } \\
\end{array}$ & $\begin{array}{c}92,3 \\
\text { Média OCDE } \\
\end{array}$ & $\begin{array}{c}92,8 \\
\text { Média OCDE } \\
\end{array}$ \\
\hline $\begin{array}{c}94,1 \\
\text { Brasil }\end{array}$ & $\begin{array}{c}90,9 \\
\text { Brasil }\end{array}$ & $\begin{array}{c}89,5 \\
\text { Brasil }\end{array}$ & $\begin{array}{c}76,5 \\
\text { Brasil }\end{array}$ \\
\hline
\end{tabular}

Fonte: Mostafa e Pál (2018) 
Revista Educação e Políticas em Debate - v. 8, n. 2, p.233-253, mai./ago. 2019 - ISSN 2238-8346

Diferentemente na Tabela 6, os dados apresentados para professores brasileiros sugerem identificação com o ambiente de trabalho embora não sendo tão valorizados no emprego, o que se acredita ter relação com a baixa remuneração, falta de formação continuada e percepção da sociedade com relação à atividade formativa.

Para a maioria dos países e economias, professores satisfeitos com a profissão tendem a estar satisfeitos também com o emprego atual. O Brasil é uma exceção que mostra maior satisfação com o trabalho do que com a profissão. A distribuição etária dos professores de ciências é considerada importante porque reflete a dinâmica de contratação dos profissionais. O país está entre os países com professores mais jovens, o que pode revelar a baixa taxa de retenção de profissionais.

A distribuição dos professores de Ciências por idade no Brasil está: mais de 15\% têm até 30 anos de idade; 65\% têm entre 30 e 50 anos de idade; média de 40 anos de idade. Os professores de Ciências do Brasil têm em média 14 anos de experiência na profissão, sendo que $86 \%$ trabalham na docência há mais de 5 anos. No emprego atual, a média de tempo foi de 7 anos para os professores do Brasil, muito próximo à média dos países da OCDE, de 8 anos.

Quase 95\% dos professores de Ciências, considerando todos os países e economias, declaram trabalhar em apenas uma escola. No Brasil esse percentual é de 65\%, o mais baixo de todos os participantes. Apenas no Brasil e no Chile o percentual de professores que trabalham em mais de uma escola excede os $10 \%$, com valores de $35 \%$ e $15 \%$, respectivamente. No Brasil, $37 \%$ dos professores trabalham na mesma escola em tempo integral, o que é uma tendência em estarem mais satisfeitos do que os demais (OCDE; INEP,2015).

No Brasil, 95\% dos professores de Ciências declaram ter frequentado curso de licenciatura autorizado pelo Ministério da Educação (MEC), já em pós-graduação são 12\%. A percepção sobre falta de recursos educacionais no Brasil considera que frequentemente prejudica a instrução. Os resultados mostram um círculo vicioso entre as gerações de professores de ciências, uma vez que professores que foram estudantes motivados são mais propensos a se sentirem satisfeitos com a profissão. Melhor clima de disciplina nas escolas, colaboração entre os professores e maior fornecimento de oportunidades para desenvolvimento profissional possivelmente têm efeito mais significativo no desempenho dos estudantes e na satisfação dos professores ao mesmo tempo. 
Revista Educação e Políticas em Debate - v. 8, n. 2, p.233-253, mai./ago. 2019 - ISSN 2238-8346

\section{Considerações}

Podemos observar pelos dados coletados que o desempenho dos estudantes brasileiros está abaixo da média dos estudantes de outros países conforme a OCDE; em ciências 401 pontos comparados com 493 pontos na média, em leitura 407 pontos comparados com 493 pontos na média e em Matemática 377 pontos comparados com 490 pontos na média.

Todos os pontos mensurados relativos ao Brasil, em edições anteriores em comparação com o PISA 2015, tem estatisticamente se mantido, ou seja, não houve evolução significativa.

O produto interno bruto (PIB) per capita do Brasil em 2015 (US\$ 15 893) correspondeu a menos da metade da média do PIB per capita nos países da OCDE (US\$ 39 333). O custo acumulado por estudante entre 6 e 15 anos de idade no Brasil (US\$ 38 190) equivale a 42\% da média de gasto por estudante em países da $\operatorname{OCDE}(\mathrm{US} \$ 90$ 294).

O Chile com gasto por aluno semelhante ao Brasil (US\$ 40 607) obteve uma pontuação melhor em Ciências (477 pontos), sendo melhores também a Colômbia, o México e o Uruguai com custo médio por estudante inferior.

Nos cabe refletir sobre a forma de gestão dos recursos implementados nas esferas municipal, estadual e federal e verificar se os mesmos estão sendo bem aplicados, ou seja, ser bem aplicado depende não somente de políticas públicas, mas também na melhor forma de gestão pedagógica, o que nem sempre docentes estão preparados para planejar e executar investimentos.

Esse investimento pedagógico perpassa por reformas nos currículos que precisam ser revisados e atualizados com maior frequência e de forma dinâmica.

Outra informação que os dados coletados nos apresentam é relativo à autonomia dos estudantes. O modelo da escola autônoma pressupõe que a autonomia do aluno seja guiada, em outras palavras, deve haver diretrizes curriculares e educacionais que permitam que ao idealizarmos aulas atraentes não percamos instrumentos de aferição do aprendizado.

Para isso faz-se necessário investimento específico e focado na formação de professores. O resultado do PISA 2015 demonstrou por meio do questionário aplicado aos docentes, que existe uma necessidade de crescimento dos profissionais, que em muitos casos se traduz em educação continuada e aperfeiçoamento pedagógico.

Na avaliação e percepção dos dados coletados, a principal preocupação dos professores está nas condições de trabalho, ou seja, poder prover materiais educacionais e infraestrutura adequada 
Revista Educação e Políticas em Debate - v. 8, n. 2, p.233-253, mai./ago. 2019 - ISSN 2238-8346

para o aprendizado dos estudantes. Para que possamos ter uma participação efetiva dos alunos como protagonistas no aprendizado, um mínimo de suporte pedagógico deve ser ofertado.

Vislumbramos pelas escolas Brasil afora, muitas iniciativas de superação das dificuldades, mas para que estejamos preparados para as próximas avaliações precisamos garantir o acesso a conteúdo e formas de disseminar o conhecimento diferenciados tais como os das tecnologias educacionais.

O PISA sendo tomado como instrumento externo de referência, internacionalmente reconhecido e segundo a Lei Federal, $\mathrm{n}^{\circ}$ 13.005, em junho de 2014 (BRASIL, 2014), na estratégia 7.11 , da sua meta 7 projeta melhoria do desempenho dos estudantes da educação básica com média dos resultados em Matemática, Leitura e Ciências de 438 (2015), 455 (2018) e 473 (2021) requer a implementação de alinhamento entre a Base Nacional Comum Curricular (BNCC), revisão dos cursos de formação inicial e continuidade professores e sua valorização na sociedade brasileira atraindo e prestigiando jovens para as carreiras de licenciaturas.

Por fim, a sociedade civil precisa cobrar dos governos em todas as esferas a aplicação eficaz e eficiente dos recursos para termos escolas e educação de qualidade. Definir critérios objetivos do que é a qualidade a ser alcançada como meta, ações efetivas contra a evasão escolar, a concretização da escola em tempo integral, a meritocracia para todos os atores envolvidos, a inserção de adjetivos no dia a dia da escola, tais como: equidade, simplicidade, inclusão, cidadania, cooperação, criatividade, inovação, interdisciplinaridade, dentre outros.

A melhoria do acesso à escola, o diálogo entre escola e sociedade, as parcerias público-privadas e a definição de políticas de Estado na educação para continuidade dos programas e projetos são imprescindíveis para aderirmos ao PISA e galgarmos melhores posições e realmente passarmos por uma mudança transformadora em um País que se encontra em uma situação grave de estagnação da educação em patamares inaceitáveis para a $9^{\text {a }}$ economia do Mundo até o momento. 
Revista Educação e Políticas em Debate - v. 8, n. 2, p.233-253, mai./ago. 2019 - ISSN 2238-8346

\section{Referencias}

BRASIL. Plano Nacional de Educação (2006). Lei $\mathrm{N}^{\mathrm{o}}$ 11.274, de 6 de fevereiro de 2006. Disponível em: < http://www.planalto.gov.br/ccivil_03/_ato20042006/2006/lei/11 1274.htm> Acesso em : 02 mai. 2019.

BRASIL. Plano Nacional de Educação (2014). Lei No 13.005, de 25 de junho de 2014. Disponível em: <http://www.planalto.gov.br/ccivil_03/_ato2011-2014/2014/lei/113005.htm> Acesso em: O2 mai. 2019.

CARVALHO, L. M. The Fabrication and Travel of a Knowledge-Policy Instrument. European Educational Research Journal, London, v. 11, n. 2, p. 172-188, 2012.

FERREIRA, M. S. Os Centros de Pesquisas Educacionais do INEP e os estudos em ciências sociais sobre a educação no Brasil. Revista Brasileira deEducação. São Paulo. v. 13 n. 38 maio/ago, p. 279-292, 2008.

MORGAN, C. Constructing the OECD Programme for International Student Assessment. In: PEREYA, Miguel (Org.). PISA under Examination: ChangingKnowledge, Changing Tests, and Changing Schools. Rotterdam: Sense Publishers,2011. P. 47-59.

MOSTAFA, T. PÁL, J. Science teachers'satisfaction: evidence from the PISA 2015 teacher survey. Paris: OECD Publishing, 2018. (OECD Education Working Papers, n. 168).

Oliveira, D. A.; JORGE, T. S. As Políticas de Avaliação, osDocentes, e a Justiça. Currículo sem Fronteiras, Braga, v. 15, n. 2, p. 346-364,maio/ago. 2015. Disponível em:<http://www.curriculosemfronteiras.org/vol 15iss2articles/oliveira-jorge.pdf $>$. Acesso em: 03 mai. 2019.

ORGANIZATION FOR ECONOMIC COOPERATION AND DEVELOPMENT. PISA 2015: results: colaborative problem solving. Paris: PISA, OECD Publishing, 2017 v.5.

ORGANIZATION FOR ECONOMIC COOPERATION AND DEVELOPMENT. PISA Assessment and Analytical Framework: Science, Reading, Mathematical and Financial Literacy, 2015. Disponível em: < https://www.oecd.org/publications/pisa-2015-assessment-and-analyticalframework-9789264281820-en.htm>. Acesso em: 02 mai. 2019.

PETTERSSON, D. Three Narratives: national interpretations of PISA. Knowledge Cultures, Woodside, v. 2, n. 4, p. 172, 2014.

PINI, G. À Propos de la Théorie des réponses aux items: le casd'itemsdichotomiques. Genebra: GroupeEdumétrie, 2012 Disponível em: <https://www.irdp.ch/data/secure/1952/document/TRI_DICHO.pdf>. Acesso em: 09 mai. 2019.

SCHWARTZMAN, S. Uses and Abuses of Education Assessment in Brazil.Prospects, Paris, v. 43, n. 3, p. 269-288, 2013. Disponível em: <https://doi.org/10.1007/s11125-013-9275-9>. Acesso em: 08mai. 2019. 
Revista Educação e Políticas em Debate - v. 8, n. 2, p.233-253, mai./ago. 2019 - ISSN 2238-8346

VILLANI, M. The Production Cycle of PISA Data in Brazil: the history of data beyond the numbers. Sisyphus Journal of Education, Lisboa, v. 6, n. 3,p. 30-52, 2018.

VILlani, M. OLIVEIRA, D.A. Avaliação Nacional e Internacional noBrasil: os vínculos entre o PISA e o IDEB. Educação \& Realidade, Porto Alegre, v. 43, n. 4, p. 1343-1362, out./dez. 2018. http://dx.doi.org/10.1590/2175-623684893 